\title{
Opioid Inhibition of Intercalated Input to the Central Amygdala
}

\author{
Matthew T. Soleiman \\ Neuroscience Graduate Program and Department of Biochemistry, University of Washington, Seattle, Washington 98195 \\ Review of Blaesse et al.
}

The neural circuitry of fear conditioning and extinction has provided an entry point to understanding and potentially improving treatment of anxiety disorders, which affect approximately one in five adults in the United States (Kessler et al., 2005). Classical fear conditioning, more recently referred to as threat conditioning, involves pairing an unconditioned stimulus (US), commonly pain in the form of foot shock, with a neutral, but predictive conditioned stimulus (CS) (LeDoux, 2014). This type of conditioning recruits a number of serial and parallel neural circuits across amygdala nuclei (Ehrlich et al., 2009).

US and CS signals appear to converge in both the lateral amygdala (LA) and central amygdala (CeA) (Blair et al., 2001; Han et al., 2015). The LA provides monosynaptic excitatory input to the CeA (Li et al., 2013), as well as to neurons of the basolateral amygdala (BLA) that in turn excite CeA neurons (Namburi et al., 2015; Fig. 1). BLA neurons project to neurons of both the medial and lateral/capsular subdivisions of the CeA (CeM and CeL, respectively) (Tye et al., 2011; Namburi et al., 2015). CeM neurons ultimately coordinate conditioned fear expression via di-

\footnotetext{
Received July 6, 2015; revised Aug. 26, 2015; accepted Aug. 31, 2015.

I thank Carlos A. Campos for his invaluable comments.

The author declares no competing financial interests.

Correspondence should be addressed to Matthew T. Soleiman, Mag-

nuson Health Sciences Center, University of Washington, Seattle, WA 98195. E-mail:msoleima@uw.edu.

DOI:10.1523/JNEUROSCI.2578-15.2015

Copyright $\odot 2015$ the authors $\quad 0270-6474 / 15 / 3513272-03 \$ 15.00 / 0$
}

vergent projections to extra-amygdala targets (Ehrlich et al., 2009; Ciocchi et al., 2010; Fig. 1). Because some BLA neurons respond to the CS (Herry et al., 2008), they contribute to fear conditioning via CeM projections (Namburi et al., 2015).

Situated between amygdala nuclei are clusters (medial and lateral) of GABAergic intercalated cells (ITCs) essential for fear extinction (Likhtik et al., 2008), although they may also be important for fear conditioning (Asede et al., 2015). Medial ITCs integrate input from both local (i.e., BLA) and distal sources (e.g., the infralimbic cortex) and they potently inhibit CeM neurons. Therefore, BLA neurons directly excite and indirectly inhibit CeM neurons (Fig. 1). In addition to responding during conditioning, BLA neurons also respond to the CS during extinction (Herry et al., 2008), allowing them to provide feedforward inhibition onto CeM neurons in a stimulus-specific manner to prevent fear expression. Consistent with this, extinction training enhances BLA-evoked inhibition onto CeM neurons via ITCs (Amano et al., 2010).

ITCs express many types of receptors (Marowsky et al., 2005; Marowsky and Vogt, 2014), suggesting their activity and consequently feedforward inhibition of CeM neurons are subject to diverse forms of regulation. In particular, ITCs display high levels of the $\mu$-opioid receptor (MOR), which binds endogenous opioids. Indeed, this enriched expression was previously exploited by Likhtik et al. (2008) to target and ablate ITCs to test their role in behavior. Yet, how
MOR activation affects ITCs and how such activation affects feedforward inhibition of CeM neurons had not been shown until recently. Blaesse et al. (2015) demonstrate that MOR-mediated inhibition of ITCs dampens BLA-evoked feedforward inhibition of CeM neurons, and that such action works against plasticity in this circuitry.

To test the effect of opioids on ITCs' resting membrane potential, the authors recorded from these neurons in brain slices of GAD67-GFP mice (which allow visualization of GABAergic neurons) while bath applying DAMGO, a MOR agonist. DAMGO hyperpolarized both lateral and medial ITCs, even in the presence of tetrodotoxin, and this effect was blocked by the MOR antagonist CTAP. Therefore, it appears that MOR activation inhibits ITCs, consistent with the receptors coupling to $G_{i / o}$ signaling, which opens inwardly rectifying potassium channels. This opioid-induced hyperpolarization reduced ITC firing and decreased feedforward inhibition of CeM neurons, as DAMGO reduced the number of action potentials generated by depolarizing current injection and attenuated the amplitude and fidelity of BLA-evoked IPSCs recorded from CeM neurons, respectively.

To more directly probe ITC input to CeM neurons, the authors uncaged glutamate specifically in the medial ITC cluster while recording from CeM neurons. While not affecting the amplitude of CeM IPSCs, DAMGO application during glutamate uncaging increased their failure rate, implying that opioids reduce the probability of GABA release onto CeM neu- 


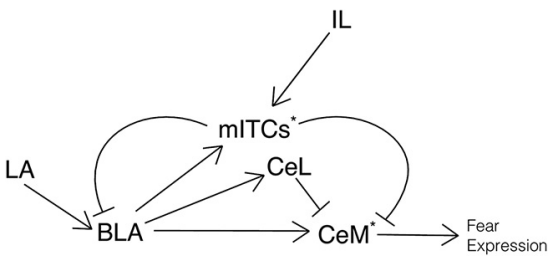

Figure 1. Simplified diagram of amygdala circuitry. Arrowheads represent excitation and flatheads represent inhibition. Asterisks represent location of MOR expression. BLA, basolateral amygdala; CeL, lateral/capsular central amygdala; CeM, medial central amygdala; IL, infralimbic cortex; LA, lateral amygdala; mITCs, medial intercalated cells. Note that the CeL and CeM together compose the CeA.

rons without affecting their postsynaptic GABA receptors. This, however, does not show whether this reduction is due to membrane hyperpolarization and/or effects on machinery involved in synaptic vesicle exocytosis.

Because the MORs have been shown to control long-term potentiation elsewhere in the brain via GABAergic transmission (Bramham and Sarvey, 1996), the authors hypothesized that MOR-mediated inhibition of ITCs might play a role in plasticity of feedforward inhibition from the BLA to the CeM. To test this idea, theta burst stimulation (TBS) was applied to the BLA either alone or in the presence of the MOR antagonist CTAP following baseline stimulation. Although no plasticity occurred with TBS alone, CTAP enabled potentiation of evoked IPSCs in CeM neurons. This suggests that either tonic or phasic (TBS-evoked) release of endogenous opioids usually inhibits plasticity within this circuitry. The authors speculate that excitatory input to ITCs is potentiated during TBS, but is opposed by MOR-mediated inhibition of ITCs, thereby preventing otherwise exaggerated inhibition of CeM neurons. In support of this idea, BLA synapses onto ITCs can undergo activitydependent plasticity (Royer and Paré, 2002).

Since BLA neurons monosynaptically excite CeM neurons, excitatory and inhibitory postsynaptic currents onto CeM neurons temporally overlap. To detect any effects of MORs on BLA-evoked excitation of CeM neurons, the authors applied ionotropic and metabotropic GABA receptor antagonists. DAMGO failed to change evoked EPSCs, providing conclusive evidence that inhibitory rather than excitatory transmission mediates the effects of MORs.

Blaesse et al. (2015) focused on how MOR activation of ITCs decreased feedforward inhibition of CeM neurons, but
ITCs have recently been shown to provide feedback inhibition of BLA principal neurons as well: that is, BLA neurons excite and are subsequently inhibited by some ITCs (Asede et al., 2015; Fig. 1). In fact, by filling individual neurons, Asede et al. (2015) identified collaterals to the BLA in a subset of CeM-projecting neurons. Therefore, in addition to influencing ITCmediated inhibition of the CeM, MORs might also modulate feedback to BLA neurons. By decreasing feedforward inhibition of CeM neurons and feedback inhibition of BLA neurons, MORs might enhance overall CeM neuronal output. Alternatively, MORs might be selectively expressed by CeM-projecting ITCs that do not have collateral projections to the BLA. This remains to be tested.

Another question for future research is which input(s) release the opioids that activate MORs in ITCs? Identifying the neural population would be critical in relating the input's function to that of opioid transmission in ITC circuitry and hence, in extinction. Enkephalinexpressing neurons of the lateral and medial subdivisions of the CeA are adjacent to ITCs (Cassell et al., 1986). Given the density of CeL microcircuitry (i.e., local terminals) as well as localization of densecore vesicles to dendrites (Ludwig and Leng, 2006; Haubensak et al., 2010; Li et al., 2013), enkephalin could perhaps reach ITCs via volume transmission (Banghart and Sabatini, 2012). This may occur under conditions like TBS, where highfrequency BLA excitatory input to $\mathrm{CeL}$ and/or CeM neurons would result in the release and volume transmission of enkephalin. As previously mentioned, this would guard against CeM neurons being overly inhibited by ITCs. Of course, there could also be extra-amygdala input of opioids.

ITCs are not the only node whereby MORs can scale input to the CeA. Blaesse et al. (2015) also observed direct inhibition of a subset of CeM neurons during DAMGO application. This is consistent with CeM neurons being inhibited by neurons of the CeL that coexpress protein kinase $\mathrm{C} \delta$ and enkephalin (Haubensak et al., 2010; Fig. 1). Moreover, CeL-projecting excitatory neurons of the parabrachial nucleus express MORs (Chamberlin et al., 1999). The CeL also receives strong input from excitatory neurons of the paraventricular thalamus, which express moderate levels of MORs (Ding et al., 1996; Penzo et al., 2015). As parabrachial or thalamic input would excite CeL neurons that in turn would inhibit CeM neurons, MOR activation in either these upstream populations should reduce downstream CeM neuron inhibition, like MOR activation in ITCs. Hence, there are multiple routes by which MORs can influence CeM activity, either individually or in parallel.

Lastly, MORs are only one of the many types of receptors expressed by ITCs. For example, ITCs also express D1 dopamine receptors and tonic-conductance $\mathrm{GABA}_{\mathrm{A}}$ receptors containing $\delta$ and $\alpha-4$ subunits (Marowsky et al., 2005; Marowsky and Vogt, 2014). Therefore, opioid action likely interacts with other forms of neuromodulation to shape ITC activity and consequently fear extinction. Gaining a complete picture of ITC function may therefore benefit from testing how different receptors together affect ITCs as an inhibitory input to the CeA.

\section{References}

Amano T, Unal CT, Paré D (2010) Synaptic correlates of fear extinction in the amygdala. Nat Neurosci 13:489-494. CrossRef Medline

Asede D, Bosch D, Lüthi A, Ferraguti F, Ehrlich I (2015) Sensory inputs to intercalated cells provide fear-learning modulated inhibition to the basolateral amygdala. Neuron 86:541554. CrossRef Medline

Banghart MR, Sabatini BL (2012) Photoactivatable neuropeptides for spatiotemporally precise delivery of opioids in neural tissue. Neuron 73:249-259. CrossRef Medline

Blaesse P, Goedecke L, Bazelot M, Capogna M, Pape HC, Jüngling $K$ (2015) $\mu$-opioid receptormediated inhibition of intercalated neurons and effect on synaptic transmission to the central amygdala. J Neurosci 35:7317-7325. CrossRef Medline

Blair HT, Schafe GE, Bauer EP, Rodrigues SM, LeDoux JE (2001) Synaptic plasticity in the lateral amygdala: a cellular hypothesis of fear conditioning. Learn Mem 8:229-242. CrossRef Medline

Bramham CR, Sarvey JM (1996) Endogenous activation of mu and delta-1 opioid receptors is required for long-term potentiation induction in the lateral perforant path: dependence on GABAergic inhibition. J Neurosci 16: 8123-8131. Medline

Cassell MD, Gray TS, Kiss JZ (1986) Neuronal architecture in the rat central nucleus of the amygdala: a cytological, hodological, and immunocytochemical study. J Comp Neurol 246:478-499. CrossRef Medline

Chamberlin NL, Mansour A, Watson SJ, Saper CB (1999) Localization of mu-opioid receptors on amygdaloid projection neurons in the parabrachial nucleus of the rat. Brain Res 827: 198-204. CrossRef Medline

Ciocchi S, Herry C, Grenier F, Wolff SB, Letzkus JJ, Vlachos I, Ehrlich I, Sprengel R, Deisseroth K, Stadler MB, Müller C, Lüthi A (2010) Encoding of conditioned fear in central amygdala inhibitory circuits. Nature 468:277-282. CrossRef Medline

Ding YQ, Kaneko T, Nomura S, Mizuno N (1996) Immunohistochemical localization of 
mu-opioid receptors in the central nervous system of the rat. J Comp Neurol 367:375402. CrossRef Medline

Ehrlich I, Humeau Y, Grenier F, Ciocchi S, Herry C, Lüthi A (2009) Amygdala inhibitory circuits and the control of fear memory. Neuron 62:757-771. CrossRef Medline

Han S, Soleiman MT, Soden ME, Zweifel LS, Palmiter RD (2015) Elucidating an affective pain circuit that creates a threat memory. Cell 162:363-374. CrossRef Medline

Haubensak W, Kunwar PS, Cai H, Ciocchi S, Wall NR, Ponnusamy R, Biag J, Dong HW, Deisseroth K, Callaway EM, Fanselow MS, Lüthi A, Anderson DJ (2010) Genetic dissection of an amygdala microcircuit that gates conditioned fear. Nature 468:270-276. CrossRef Medline

Herry C, Ciocchi S, Senn V, Demmou L, Müller C, Lüthi A (2008) Switching on and off fear by distinct neuronal circuits. Nature 454:600606. CrossRef Medline

Kessler RC, Chiu WT, Demler O, Merikangas KR, Walters EE (2005) Prevalence, severity, and comorbidity of 12-month DSM-IV disorders in the national comorbidity survey replication.
Arch Gen Psychiatry 62:617-627. CrossRef Medline

LeDoux JE (2014) Coming to terms with fear. Proc Natl Acad Sci U S A 111:2871-2878. CrossRef Medline

Li H, Penzo MA, Taniguchi H, Kopec CD, Huang ZJ, Li B (2013) Experience-dependent modification of a central amygdala fear circuit. Nat Neurosci 16:332-339. CrossRef Medline

Likhtik E, Popa D, Apergis-Schoute J, Fidacaro GA, Paré D (2008) Amygdala intercalated neurons are required for expression of fear extinction. Nature 454:642-645. CrossRef Medline

Ludwig M, Leng G (2006) Dendritic peptide release and peptide-dependent behaviours. Nat Rev Neurosci 7:126-136. CrossRef Medline

Marowsky A, Vogt KE (2014) Delta-subunitcontaining GABAA-receptors mediate tonic inhibition of paracapsular cells of the mouse amygdala. Front Neural Circuits 8:27. Medline

Marowsky A, Yanagawa Y, Obata K, Vogt KE (2005) A specialized subclass of interneurons mediates dopaminergic facilitation of amygdala function. Neuron 48:1025-1037. CrossRef Medline

Namburi P, Beyeler A, Yorozu S, Calhoon GG, Halbert SA, Wichmann R, Holden SS, Mertens KL, Anahtar M, Felix-Ortiz AC, Wickersham IR, Gray JM, Tye KM (2015) A circuit mechanism for differentiating positive and negative associations. Nature 520:675678. CrossRef Medline

Penzo MA, Robert V, Tucciarone J, De Bundel D, Wang M, Van Aelst L, Darvas M, Parada LF, Palmiter RD, He M, Huang ZJ, Li B (2015) The paraventricular thalamus controls a central amygdala fear circuit. Nature 519:455459. CrossRef Medline

Royer S, Paré D (2002) Bidirectional synaptic plasticity in intercalated amygdala neurons and the extinction of conditioned fear responses. Neuroscience 115:455-462. CrossRef Medline

Tye KM, Prakash R, Kim SY, Fenno LE, Grosenick L, Zarabi H, Thompson KR, Gradinaru V, Ramakrishnan C, Deisseroth K (2011) Amygdala circuitry mediating reversible and bidirectional control of anxiety. Nature 471:358-362. CrossRef Medline 